\title{
USO DE ADESIVOS TECIDUAIS EM CIRURGIA DIGESTIVA
}

\author{
Tissue adhesives in digestive surgery \\ Cleber SOARES-JÚNIOR, Camila Couto GOMES, Rodrigo de Oliveira PEIXOTO, \\ Carlos Augusto GOMES, Claudio de SOUZA
}

Trabalho realizado na Universidade Federal de Juiz de Fora, Juiz de Fora, MG, Brasil

DESCRITORES - Adesivo. Trato gastrointestinal. Anastomose cirúrgica. Fístula.
RESUMO - Introdução: Apesar dos refinamentos em cirurgia gastrointestinal, vazamentos anastomóticos persistem como grave problema, associados à morbidade e mortalidade elevadas e constituem a complicação mais temida. $\mathrm{Na}$ tentativa de prevenir e reduzir estas complicações, diversidade de técnicas de reforço anastomótico tem sido investigada e diversas medidas auxiliares têm sido desenvolvidas. Objetivo - Revisar os dados associados a aplicação de adesivos em cirurgia digestiva. Método - Revisão bibliográfica de artigos disponíveis no Medline/Pubmed utilizando-se os descritores: adesivo, trato gastrointestinal, anastomose cirúrgica e fístula. Foram selecionados os artigos mais atualizados sobre o assunto os quais utilizaram adesivos como estratégia para reduzir a morbidade e mortalidade relacionada à cirurgia digestiva. Conclusão - Adesivos teciduais parecem seguros na prática clínica e têm sido utilizados com crescente frequência em várias especialidades cirúrgicas em decorrência de suas propriedades hemostáticas e selante, ganhando cada vez maior aceitação por parte dos cirurgiões. Estudos sugerem que adesivos cirúrgicos podem reforçar e melhorar a cicatrização de anastomoses intestinais, elevando a pressão de ruptura e aumentando a força tênsil. Os potenciais efeitos deletérios teciduais destas substâncias podem limitar sua utilização. Em decorrência da heterogeneidade dos estudos e falta de evidência forte, novas pesquisas deverão ser desenvolvidas.

\section{Correspondência: \\ Cleber Soares Júnior, \\ e-mail: cleberdoc@ig.com.br \\ Fonte de financiamento: não há \\ Conflito de interesses: não há}

Recebido para publicação: 31/05/2010

Aceito para publicação: 15/05/2010

HEADINGS - Adhesive. Gastrointestinal tract. Surgical anastomosis. Fistula.
ABSTRACT - Background - Despite refinements in the field of gastrointestinal surgery, anastomotic leakage still remains a serious problem associated with substantial morbidity and mortality and is the fearest life threatening complication in digestive surgery. To prevent or reduce these complications, a diversity of line reinforcement techniques have been investigated and several adjunctive measures have been developed. Aim - To review the data associated with the application of adhesives in digestive surgery procedures. Method - Review of papers available at Medline/Pubmed database using the follow headings: adhesive, gastrointestinal tract, surgical anastomosis, fistula. It was chosen recent articles on the subject which showed adhesives as strategy to reduce morbidity and mortality related to digestive surgery. Conclusion - Tissue adhesives appears to be safe in the clinical setting and are been used with increasing frequency in a variety of surgical field for its unique hemostatic and adhesive abilities, gaining increasing acceptance among surgeons. Studies suggest that surgical adhesive can be useful to reinforce and improve intestinal anastomotic healing, increase anastomotic bursting pressures and tensile strength. The potentially harmful tissue effects of the preparations might compromise the use of these substances. Because of the heterogeneity and lack of high level evidence, new studies have to be performed.

\section{INTRODUÇÃO}

busca por uma anastomose impermeável tem sido fato constante
nas operações gastrointestinais. Deiscência anastomótica
representa a complicação mais temida a que está sujeito o paciente submetido à cirurgia do aparelho digestório ${ }^{7,8}$. O risco é maior nas anastomoses com o pâncreas, esôfago, cólon e reto extraperitoneal, mas pode ocorrer em qualquer tipo de anastomose ${ }^{1,4}$.

A pesquisa de um método seguro para anastomoses tem ocorrido nos últimos dois séculos, com desenvolvimento de técnicas e materiais, e 
melhor entendimento do processo cicatricial ${ }^{4,26}$. Entre os fatores que agregam risco às anastomoses, está o grau de contaminação da víscera empregada (este fator interfere ativamente no balanço entre a síntese e deposição de colágeno); a presença do conteúdo intraluminal promove forças de cisalhamento que interferem no processo; a distensão local pelo conteúdo também pode desencadear isquemia na área suturada.

O avanço científico e tecnológico promoveu, além do aperfeiçoamento dos tipos de fios e das técnicas de sutura, também o desenvolvimento de laser, grampeadores mecânicos, protetores intraluminais da linha de sutura e adesivos teciduais naturais e sintéticos ${ }^{1,4,8,20}$.

\section{A utilização de adesivos em cirurgia}

Segundo Fontes, foi um artista circense de nome Gamba Curta, o primeiro a utilizar um composto para colar tecido biológico, no século XIX. Ele retirava fragmentos da própria pele e depois a colava ${ }^{11}$. A utilização de adesivos teciduais em cirurgia foi proposta por Young \& Medawar em 1940; somente a partir de 1960 iniciaram-se estudos sistemáticos na aplicação destes materiais ${ }^{26,27}$.

No início do século, começaram as pesquisas com adesivos derivados de coágulos solidificados de fibrina, inclusive com aplicação sobre suturas intestinais. A partir da década de 70, o adesivo de fibrina adquiriu importância em virtude de sua propriedade selante e hemostática. A era moderna da utilização deste tipo de substância em cirurgia, tem início com os trabalhos de Helene Matras, que usou fibrina em anastomoses intestinais em $1977^{11}$.

$\mathrm{Na}$ década de 1950 determinaram-se as características dos acrilatos. Suas propriedades adesivas e seu rápido enrijecimento foram descritas, sugerindo sua utilização em cirurgia. Diversos autores a partir da década de 60 estudaram as formulações disponíveis dos acrilatos no trato gastrointestinal, inclusive com aplicação em seres humanos ${ }^{11,23}$.

\section{Fundamentos sobre adesivos teciduais}

Adesivos teciduais são definidos como substâncias com propriedades químicas de polimerização, e que formam precipitado sólido. Têm sido cada vez mais utilizados em diversas especialidades inclusive cirurgia digestiva $3,5,7,13,17,23$. Sua indicação pode ser dividida em quatro categorias: 1) hemostasia, 2) selante, 3) como meio de transporte de substâncias exógenas (medicamentos, quimioterápicos, fatores de crescimento) a determinadas regiões e órgãos e 4) como agente na prevenção de aderências ${ }^{14,17,23}$.

Estes compostos mantêm os tecidos em posição para permitir a cicatrização de áreas cruentas contíguas e servem de barreira aos extravasamentos ${ }^{23,26}$. A velocidade e a forma de solidificação dependem da substância em questão e da superfície em que é aplicada, podendo ser influenciados pelo $\mathrm{pH}$, umidade e luminosidade ${ }^{27}$.
A adesão induzida é obtida por meio de ligações químicas tipo iônica (primária), covalente e metálica; e/ou física tipo van der Waals. As ligações primárias são capazes de promover adesão eficiente em tecidos vivos. Grupos amino, hidroxil e carboxil, encontrados em colágeno, têm potencial de reação capaz de levar à adesividade. Estes radicais estabelecem ligações iônicas com os radicais do adesivo promovendo união ${ }^{27}$.

Os adesivos podem ser classificados em sintéticos e naturais. Os primeiros incluem o cianoacrilato e a associação albumina-resorcinol-formaldeídoglutaraldeído (GRF). Entre os biológicos incluem-se os adesivos a base de fibrina, o colágeno associado à trombina e polímeros de polietilenoglicol (hidrogel). Estes compostos naturais se utilizam das mesmas propriedades que os tecidos vivos para causar hemostasia e adesão, são menos tóxicos e induzem menor reação inflamatória $13,16,17,23,26,27$.

Um adesivo de características ótimas, ainda não disponível, deve ser seguro, agir apenas localmente, não interferir com o processo natural de restitutio ad integrum do tecido e somente se degradar após o tempo completo de cicatrização ${ }^{5,23,26,27}$. Além disso, atributos desejáveis do composto incluem facilidade de manuseio e conservação, insolubilidade em água, solidificação rápida, ausência de efeito carcinogênico, tóxico ou alergênico ${ }^{27}$.

\section{Adesivos de fibrina}

Selantes a base de fibrina são uma combinação de cálcio, trombina, fibrinogênio $(70-110 \mathrm{mg} / \mathrm{mL})$, fator XIII (10 a 50 UI), e um antifibrinolítico, como a aprotinina (inibidor de protease) ou acido tranexâmico. Têm sido descritos como adesivos fisiológicos ideais ${ }^{17}$. O adesivo evita hematomas por meio da oclusão de pequenos vasos, facilitando a união das bordas. A presença de fator XIII no composto estimula a migração de fibroblastos. A fibrina e fibronectina formam arcabouço para neoformação vascular e fibroplasia.

Embora inicialmente utilizados com intenção hemostática, posteriormente coágulos de fibrina foram utilizados para promover aderência entre estruturas. Suas propriedades hemostática, oclusiva, adesiva, promotora da cicatrização (estímulo ao crescimento dos fibroblastos) e antisséptica conferem-Ihe uma gama de aplicações clínicas ${ }^{6,17}$.

Existem diversos estudos, prospectivos e padronizados, com adesivos de fibrina. Aplicações em cirurgia gastroenterológica incluem: prevenção de aderências peritoneais, cirurgia esplênica, hepatectomias, prevenção e tratamento de fístulas

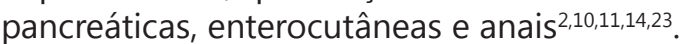

Em geral, são usados pela sua segurança e pelo risco mínimo de transmissão de infecções ${ }^{23}$. A possibilidade de obtenção de fibrinogênio de apenas um doador ou do próprio paciente diminuiu o risco de transmissão viral e ampliou o uso clínico da fibrina. Este aspecto é importante conquanto exista relação direta entre a força 
tênsil e o conteúdo de fibrinogênio da mistura ${ }^{27}$.

Mesmo com ótima formação do precipitado, estes são produtos biológicos, e por isso são degradados em período variável de tempo, dependendo da preparação, volume e local de aplicação. A força de coesão depende, em última instância, da interação molecular com o tecido vivo.

O uso isolado de adesivos de fibrina em anastomoses tem ocorrido apenas em modelos experimentais ${ }^{17,28}$, de outra forma sua utilização em humanos tem se restringido ao reforço das suturas do trato gastrointestinal e aplicação em áreas cruentas ${ }^{3,4,17}$. Sua aplicação propicia cicatrização mais rápida, com incidência de vazamentos inferior ao do grupo controle, inclusive considerando anastomoses esofágicas, esofagojejunais e colônicas ${ }^{15}$. Sua utilização concomitante com grampeadores mecânicos trouxe benefícios no que diz respeito à prevenção de vazamentos e velocidade de cicatrização ${ }^{4}$.

Pesquisas em outras áreas também parecem promissoras como fechamento de fístula traqueoesofágica e fechamento de fístulas digestivas simples e complexas s.2. $^{3,29}$. A associação com hormônio do crescimento parece mostrar efeito sinérgico na cicatrização anastomótica. Entretanto, autores atribuem os benefícios à presença da fibrina e não do hormônio, conquanto a utilização isolada do adesivo comparada à utilização isolada do hormônio do crescimento é superior, apresentando maiores pressões de ruptura, neoangiogênese, deposição de colágeno e conteúdo anastomótico de hidroxiprolina, além de menores dosagens de mieloperoxidase tecidual ${ }^{30}$. Estudos têm evidenciado que anastomoses intestinais com adesivos de fibrina mostram melhor cicatrização, seja no que diz respeito aos aspectos micro e macroscópicos, seja na maior resistência a pressão de rotura ${ }^{17}$.

Adesivos de fibrina têm sido utilizados com frequência na redução (profilaxia) de fístulas biliares e sangramento de área cruenta pós-ressecção hepática. Trabalhos mostram menor intensidade de aderências quando a fibrina é aplicada. Os escores histopatológicos também foram melhores quando comparados com a sutura convencional ${ }^{6}$.

Têm sido utilizados em complicações de anastomoses pancreáticas com resultados satisfatórios. Entretanto, metanálise sobre o uso destes adesivos em cirurgia pancreática mostraram-se inconclusivos em decorrência da heterogeneidade e falta de evidência à sua utilização ${ }^{10,16}$.

Sua aplicação sobre anastomoses colônicas mostrou resultados favoráveis quanto às pressões e forças de ruptura ${ }^{1}$. De outra forma, a utilização rotineira de adesivos de fibrina no tratamento de fístulas anais ainda mostra resultados desanimadores e carece de maiores estudos ${ }^{18}$.

Adesivo de albumina-resorcinol-formaldeídoglutaraldeído (GRF)

A associação de albumina com resorcinol permite ao composto similaridades com o tecido conjuntivo. Ele aumenta a resistência da mistura, em virtude da capacidade de se condensar na presença de formaldeído, no entanto, a velocidade e a totalidade da reação são dependentes do $\mathrm{pH}$. Ambos (resorcinol e formaldeído) têm poder germicida, apresentam irritação local na dependência das concentrações, mesmo sendo desprovidos de toxicidade sistêmica ${ }^{27}$.

Assim como o adesivo de fibrina, o GRF é biodegradável e pode ser usado com intenção hemostática e na prevenção de extravasamentos. Entre suas vantagens está a possibilidade de ser aplicado em superfícies úmidas e não representar barreira à cicatrização ${ }^{27}$. Tem vida-média de 30 dias $^{23}$.

O GRF foi utilizado experimentalmente em diversos tecidos, inclusive anastomoses gastrointestinais ${ }^{23,27}$.

Comparados com adesivos de fibrina, mostraram pior integração tecidual, maior quantidade de aderências e deslocamentos, e maior reação tipo corpo estranho. $O$ adesivo de albumina associado à glutaraldeído mostrou boa força adesiva, mas baixa biocompatibilidade.

Apesar de resultados desanimadores no passado, recentemente este tipo de adesivo tem sido estudado como forma de evitar vazamentos e fístulas em anastomoses gastrointestinais, inclusive esofagorrafias. Uso experimental de adesivo de albumina/glutaraldeído sobre anastomose com grampeador mecânico parece determinar reforço das anastomoses que se traduziu como uma maior resistência à pressão de ruptura, sua utilização em anastomoses intactas e defectivas ${ }^{7}$.

Lämsä comparou seis tipos de adesivos em anastomoses pancreaticojejunais. Todos os compostos (dois a base de fibrina, três tipos de cianoacrilatos, um adesivo de albumina/glutaraldeído) induziram alterações histológicas no pâncreas. Os efeitos foram piores com os cianoacrilatos, mas os adesivos de fibrina apresentaram menor força tênsil. O GRF apresentou resultados intermediários entre as outras duas classes de adesivos ${ }^{16}$.

\section{Adesivos de hidrogel}

Hidrogel (polímeros de polietilenoglicol) são agentes solúveis em água, ativados pela luz (fotopolimerização) e absorvidos em período de três meses. Apresentam processo de aplicação complicado, mas têm grande potencial para utilização. As vantagens de sua aplicação incluem: compostos sintéticos (risco reduzido de transmissão de doenças), biodegradação, polimerização rápida e sem liberação de calor, ausência de toxicidade local, boa adesão tecidual e promoção de angiogênese ${ }^{19}$.

No que diz respeito à cirurgia do aparelho digestório, foram utilizados experimentalmente para reduzir a exposição intestinal ao líquido amniótico em animais com gastrosquise com bons resultados ${ }^{12}$.

\section{Adesivos de colágeno}

Adesivos a base de colágeno são combinação de colágeno e trombina bovinos. Funcionam promovendo uma matriz para o coágulo e fornecendo 
fibrinogênio para o local. Têm grande utilidade em cirurgia, sendo de baixo custo ${ }^{23}$.

Erdogan et al compararam experimentalmente o uso de fibrina líquida com "patch" de colágeno coberto com fibrinogênio em ressecções hepáticas. Os resultados mostraram maior resistência ao aumento da pressão do sistema biliar no grupo em que se utilizou colágeno permitindo sua utilização na superfície cruenta hepática9.

Entretanto, a análise comparativa entre o uso de "patch" de colágeno associado a adesivo de fibrina e sutura sem o acréscimo do composto, em anastomoses gastrointestinais, não mostrou diferença no que se refere à histologia, pressão de ruptura e o grau de estenose ${ }^{21}$.

\section{Adesivos de cianoacrilatos}

O cianoacrilato constitui grupo de adesivos de polimerização rápida, não biodegradáveis, que têm sido cada vez mais utilizados desde a década de 1960 São utilizados principalmente como agentes anastomóticos e hemostáticos, mesmo com sua aparente toxicidade ${ }^{13,26}$.

São sintetizados a partir de reação entre formaldeído e cianoacetato, resultando em prépolímero que, por meio do calor, se despolimeriza em monômeros sob a forma líquida. O monômero pode ser modificado alterando-se o grupamento alquil (-COOR), obtendo-se substâncias com cadeias de tamanhos diferentes. O contato com íons hidroxila após sua aplicação em tecidos vivos, promove uma reação de hidroxilação exotérmica que polimeriza (polimerização aniônica) o composto e o endurece ${ }^{27}$.

A causa da toxicidade dos compostos é atribuída aos produtos de degradação, cianoacetato, formaldeído e hidroperóxidos que ativam a síntese de prostaglandinas e tromboxanos (participantes da oxidação e lise da membrana celular). A concentração local destes produtos é proporcional ao ritmo de degradação da substância polimerizada. Os compostos de éster com cadeia lateral longa (radical álcool), se degradam mais lentamente, consequentemente apresentam aderência mais forte, sendo menos reativos $^{2,13,25}$. De outra forma, os cianoacrilatos apresentam propriedades antimicrobianas contra organismos gram-positivos e alguns gram-negativos. Sabe-se que este efeito antimicrobiano aumenta com a diminuição da cadeia do grupo alquil, e que esta propriedade parece estar relacionada com a polimerização do adesivo, mas não apresenta duração longa ${ }^{27}$.

O uso dos cianoacrilatos mostrou-se insatisfatório no trato gastrointestinal em diversos estudos, com importante histotoxicidade local, abundância de tecido cicatricial, retração da mucosa, processo inflamatório crônico, infiltração granulomatosa, retardo histológico da cicatrização além de considerações sobre carcinogênese ${ }^{22,26}$. Anastomoses intestinais, utilizando os cianoacrilatos, têm sido estudadas desde a década de 60 . Frequência de vazamento entre $30 \%$ e $60 \%$, além da formação de processo inflamatório e reação tipo corpo estranho, levou ao abandono parcial destas substâncias no que se refere ao aparelho digestório ${ }^{15}$. De fato, Nordkild et ali, em trabalho de revisão, concluíram que o uso dos cianoacrilatos em anastomoses do trato gastrointestinal induzia mortalidade de $60 \%$, em contraposição a $22 \%$ do grupo controle, no qual não foi utilizado. Seu uso exclusivo determinou mortalidade de $97 \%{ }^{27}$.

Entretanto, apesar das vantagens inerentes a sua formulação e tempo de aplicação, os resultados de sua aplicação em cirurgia gastroenterológica foram desfavoráveis em virtude da intensa reação inflamatória que propiciava. Trabalhos experimentais recentes mostraram que o uso de n-butil-cianoacrilato em fístulas de anastomoses jejunojejunais de alto débito é satisfatório em termos de tolerância à pressão de rotura, apesar do aumento do número de aderências intestinais ${ }^{8}$.

O n-butil cianoacrilato tem sido considerado tratamento de escolha para varizes gástricas sangrantes em muitos países. Nos Estados Unidos, onde não estão autorizados para utilização em seres humanos, o octil-2 cianoacrilato tem sido usado como substituto ${ }^{24}$.

O polímero octil-2 cianoacrilato apresenta flexibilidade maior, melhor adaptação aos tecidos corporais, tempo mais longo de permanência e menor rompimento da estrutura tridimensional. A este respeito pode-se afirmar que a ultra-estrutura tridimensional do octil-2 cianoacrilato é três vezes mais resistente que a do butil-2 cianoacrilato, e se assemelha àquela da sutura com monofilamento 5.02,13,25.

Metanálise feita por Singer et al ${ }^{25}$. identificou 35 estudos com octil-2 cianoacrilato. Todos os trabalhos avaliados referiram-se à tratamento de lesões cutâneas: lacerações, incisões cirúrgicas - cirurgia geral, dermatologia, ginecologia e ortopedia-e experimentos em animais. Não há menção à utilização do composto no trato digestório. Sua utilização cutânea está bem estabelecida na clínica diária, embasada fortemente em estudos experimentais ${ }^{25}$.

Em relação ao trato gastrointestinal, Bahten comparou sua utilização com fio de poliglecaprone no tratamento de lesões traumáticas esplênicas. O octil-2 cianoacrilato provocou menos aderências macroscópicas e não induziu reação tipo corpo estranho².

Novos estudos procuraram estabelecer riscos e benefícios deste composto nas suturas colônicas, mas os resultados ainda são conflitantes, com importante estímulo a formação de processo inflamatório ${ }^{15,22,26}$.

O octil-2 cianoacrilato tem sido utilizado no tratamento de varizes gástricas de forma eficaz e segura. Entretanto, Rickman et ali descreveu o caso de embolização sistêmica desta substância após injeção endoscópica ${ }^{24}$. 


\section{CONCLUSÃO}

Adesivos teciduais têm sido cada vez mais utilizados em vários ramos da cirurgia em virtude de suas propriedades hemostáticas, selante, indutora da cicatrização e antimicrobiana. Estudos sugerem que alguns adesivos podem melhorar a cicatrização de anastomoses intestinais, reduzindo a incidência e tratando as deiscências das anastomoses. Efeitos adversos de sua aplicação inviabilizam sua utilização rotineira em alguns tecidos e merecem maiores estudos. Novas pesquisas deverão ser desenvolvidas para elucidar os limites da aplicabilidade dos diversos tipos de adesivos disponíveis no momento.

\section{REFERÊNCIAS}

1. Akgün A, Kuru S, Uraldi C, Tekin O, Karip B, Tug T, Ongören AU. Early effects of fibrin sealant on colonic anastomosis in rats: an experimental and case-control study. Tech Coloproctol. 2006 Oct;10(3):208-14.

2. Bahten LC, Noronha L, Silveira F, Nicollelli G, Longhi P, Pantanali CAR. Estudo da cicatrização nas lesões traumáticas esplênicas utilizando octil-2 cianoacrilato e fio de poliglecaprone25. Rev Col Brás Cir 2006;33(3):174-180.

3. Casella G, Soricelli E, Rizzello M, Trentino P, Fiocca F, Fantini A, Salvatori FM, Basso N. Nonsurgical treatment of staple line leaks after laparoscopic sleeve gastrectomy. Obes Surg. 2009 Jul;19(7):821-6.

4. Cheragwandi A, Nieuwenhuis DH, Gagner M, Consten EC. An update of available innovative staple line reinforcement materials in colorectal surgery. Surg Technol Int. 2008;17:131-7.

5. Coulthard $P$, Esposito $M$, Worthington $H V$, van der Elst $M$, van Waes OJ, Darcey J. Tissue adhesives for closure of surgical incisions. Cochrane Database Syst Rev. 2010 May 12;5:CD004287.

6. Demirel AH, Basar OT, Ongoren AU, Bayram E, Kisakurek M. Effects of primary suture and fibrin sealant on hemostasis and liver regeneration in an experimental liver injury. World J Gastroenterol. 2008 Jan 7;14(1):81-4.

7. Downey DM, Ali S, Goldblatt MI, Saxe JM, Dolan JP. Gastrointestinal staple line reinforcement. Surg Technol Int. 2007; 16:55-60.

8. Ensari CO, Genc V, Cakmak A, Erkek B, Karayalcin K. Effects of $\mathrm{N}$-butyl-2-cyanoacrylate on high-level jejunojejunostomy. Eur Surg Res 2010;44(1):13-6

9. Erdogan D, de Graaf W, van Gulik TM. Adhesive strength of fibrinogen-coated collagen patch or liquid fibrin sealant in an experimental liver resection model in pigs. Eur Surg Res. 2008;41(3):298-302.

10. Fingerhut A, Veyrie N, Ata T, Alexakis N, Leandros E. Use of sealants in pancreatic surgery: critical appraisal of the literature. Dig Surg. 2009;26(1):7-14.

11. Fontes CER, Taha MO, Fagundes DJ, Ferreira MV, Prado Filho OR, Mardegan MJ. Estudo comparativo do uso de cola de fibrina e cianoacrilato em ferimento de fígado de rato. Acta Cir Bras 2004; 19(1): 37-42.
12. Gonçalves FL, da Silva $R$, Schmidt AF, de Oliveira MG, Sbragia L. Hydrogel protection: a novel approach to reduce bowel inflammation in experimental gastroschisis. Eur J Obstet Gynecol Reprod Biol. 2010 Jan;148(1):35-9.

13. Haber GB. Tissue glue for pancreatic fistula. Gastrointest Endosc 2004; 59 (4): 535-7.

14. Imai A, Suzuki N. Topical non-barrier agents for postoperative adhesion prevention in animal models. Eur J Obstet Gynecol Reprod Biol. 2010 Apr;149(2):131-5.

15. Kanellos I, Mantzoros I, Demetriades H, Kalfadis S, Sakkas L, Kelpis $\mathrm{T}$, Betsis D. Sutureless colonic anastomosis in the rat: a randomized controlled study. Tech coloproctol 2002; 6:143-146.

16. Lämsä T, Jin HT, Sand J, Nordback I. Tissue adhesives and the pancreas: biocompatibility and adhesive properties of 6 preparations. Pancreas. 2008 Apr;36(3):261-6.

17. Lee $M G$, Jones D. Applications of fibrin sealant in surgery. Surg Innov. 2005 Sep;12(3):203-13.

18. Malik AI, Nelson RL. Surgical management of anal fistulae: a systematic review. Colorectal Dis. 2008 Jun;10(5):420-30.

19. Miller JS, Shen CJ, Legant WR, Baranski JD, Blakely BL, Chen CS. Bioactive hydrogels made from step-growth derived PEG-peptide macromers. Biomaterials. 2010 May;31(13):3736-43.

20. Mo $X$, Iwata $H$, Ikada $Y$. A tissue adhesives evaluated in vitro and in vivo analysis. J Biomed Mater Res A. 2010 Jul;94(1):326-32.

21. Nordentoft T, Rømer J, Sørensen M. Sealing of gastrointestinal anastomoses with a fibrin glue-coated collagen patch: a safety study. J Invest Surg. 2007 Nov-Dec;20(6):363-9.

22. Nursal TZ, Anarat R, Bircan S, Yildrim S, Tarim A, Haberal M. The effect of tissue adhesive, octyl-cyanoacrylate, on the healing of experimental high-risk and normal colonic anastomoses. Am J Surg 2004; 187:28-32.

23. Reece TB, Maxey TS, Kron IL. A prospectus on tissue adhesives. Am J Surg 2001; 182(2):40S-44S.

24. Rickman OB, Utz JP, Aughenbaugh GL, Gostout CJ. Pulmonary embolization of 2-octyl cyanoacrylate after endoscopic injection therapy for gastric variceal bleeding. Mayo Clin Proc. 2004; 79:1455-1458.

25. Singer AJ, Thode Jr HC. A review of the literature on octylcyanoacrylate tissue adhesive. Am J Surg 2004; 187 (2):238-248.

26. Soares junior C, Souza C. Uso de 2-octil cianoacrilato em anastomose colonicas: estudo experimental em ratos wistar. Rev Col Bras Cir. [Periódico na Internet] 2010; 37(2). Disponível em URL: http://www.scielo.br/rcbc

27. Souza C. Uso de adesivos biológicos em anastomoses intestinais - Estudo experimental em coelhos. Belo Horizonte, 1993. Tese de Doutorado. Faculdade de Medicina, Universidade Federal de Minas Gerais.

28. Stumpf M, Junge $K$, Rosch R, Krones C, Klinge U, Schumpelick $\mathrm{V}$. Suture-free small bowel anastomoses using collagen fleece covered with fibrin glue in pigs. J Invest Surg. 2009 MarApr;22(2):138-47.

29. Upadhyaya VD, Gopal SC, Gangopadhyaya AN, Gupta DK, Sharma S, Upadyaya A, Kumar V, Pandey A. Role of fibrin glue as a sealant to esophageal anastomosis in cases of congenital esophageal atresia with tracheoesophageal fistula. World J Surg. 2007 Dec;31(12):2412-5.

30. Wang P, Wang J, Zhang W, Li Y, Li J. Effect of the combination of fibrin glue and growth hormone on intestinal anastomoses in a pig model of traumatic shock associated with peritonitis. World J Surg. 2009 Mar;33(3):567-76. 